\title{
Osteopontin Promotes Cell Migration and Invasion, and Inhibits Apoptosis and Autophagy in Colorectal Cancer by activating the p38 MAPK Signaling Pathway
}

\begin{abstract}
Ren-hong Huang ${ }^{a}$ Ying-jun Quan ${ }^{a}$ Jin-hong Chen ${ }^{b}$ Ting-feng Wang ${ }^{a}$ Ming Xu Min Yea Hao Yuan ${ }^{a}$ Chong-jie Zhang ${ }^{a}$ Xiao-jian Liu ${ }^{c}$ Zhi-jun Min ${ }^{a}$

aDepartment of Gastrointestinal Surgery, Shanghai Pudong Hospital, Fudan University Pudong Medical Center, ${ }^{b}$ Department of General Surgery, Huashan Hospital, Fudan University, 'Department of Medical Oncology, Shanghai Cancer Center, Fudan University, Shanghai, China
\end{abstract}

\section{Key Words}

Osteopontin • Autophagy $\cdot$ Proliferation $\cdot$ Migration $\bullet$ Invasion $\bullet$ Apoptosis $\bullet$ Colorectal cancer - P38 MAPK pathway

\begin{abstract}
Background: Osteopontin (OPN) is highly expressed in colorectal cancer (CRC) and is associated with disease progression in vivo. High levels of OPN have been demonstrated to predict low survival rates in CRC. Autophagy is a process of self-digestion, which is thought to play a significant role in carcinogenesis. However, the mechanisms of OPN's effects on CRC cell autophagy have not been elucidated. Therefore, we aimed to investigate possible mechanisms of OPN's effects on CRC autophagy. Methods: HCT116 cell proliferation, apoptosis, and migration and invasion ability were identified by cell counting kit-8 assay, flow cytometry, wound healing assay, and transwell chamber invasion assay, respectively. The ratios of proteins LC3-II/LC3-I, P62, and Atg7 were analyzed by Western-blot. Expressions of Beclin-1, Atg4b, Bnip3, and Vps34, both in transcriptional and translational levels, were analyzed and compared by RT-PCR and Western blot. Immunofluorescence and co-focusing experiments were used to investigate the formation of autophagosomes. Results: The results showed that OPN can promote cell proliferation, migration, and invasion, as well as inhibit cell apoptosis. It was also demonstrated that OPN could inhibit cell autophagy. Further experiments revealed that the inhibitory effect of OPN on autophagy could be reversed by blocking the p38 MAPK pathway in HCT116 cells. Conclusion: OPN is involved in HCT116 cell progression and is capable of inhibiting cell autophagy possibly by activating the p38 MAPK signaling pathway, implying that OPN could be a potential novel molecular therapeutic biomarker in patients with CRC.

R.-h. Huang, Y.-j. Quan are equally to this work.

Zhi-jun Min and Xiao-jian Liu

KARGER

Department of Gastrointestinal Surgery, Shanghai Pudong Hospital, Pudong Medical Center, Fudan University; 2800, Gongwei Road, Huinan Town, Pudong, Shanghai, 201399 and Department of Medical Oncology, Shanghai Cancer Center, Fudan University, Shanghai, 200032 (China); E-Mail minzhijun@126.com/ Ixj068@hotmail.com
\end{abstract}




\section{Cellular Physiology Cell Physiol Biochem 2017;41:1851-1864 and Biochemistry Publisned online: Aprilu3, $2017 \quad \begin{aligned} & \text { D 2017 The Authors. } \\ & \text { www.karger.com/cpb }\end{aligned}$ \\ Huang et al.: Osteopontin Inhibits Apoptosis and Autophagy in Colorectal Cancer}

\section{Introduction}

Colorectal cancer (CRC), one of the most common digestive track tumors, remains the third leading cause of cancer-related mortality in both sexes worldwide and presents a great burden for both individuals and society as a whole [1]. Despite recent advances in modern medical technology, CRC remains a disease with high mortality due to local relapse, distant metastases and resistance to chemotherapy $[2,3]$. CRC is associated with multiple factors and a complex mechanism of interrelated processes, and presently, it is mainly treated by surgical removal of the focal lesions, chemotherapy in combination with radiotherapy, and other palliative methods. However, all of these therapies have their limitations. Therefore, it would be greatly desirable to find additional therapeutic biomarkers for the treatment of patients with CRC.

Osteopontin (OPN), a phosphorylated and tumor-related protein, is widespread in various tissues such as mineral compound tissues, epithelial cells, tissues related to intestinal metabolism, lymphocytes, and osteoclasts. Albumin, protein excretion together with OPN were restored in ET+/+eNOS-/- and increased in eNOS-/- animals, which indirectly served as the indicators of kidney metabolism in eNOS knockout mice model [4]. Recent studies have indicated that OPN is closely associated with the proliferation, invasion, and metastasis of various malignant tumors, such as breast cancer, hepatic carcinoma, prostate cancer, colorectal cancer, and lung cancer. Literature data concerning the association between OPN and the predictive of developing pulmonary tuberculosis are available [5]. OPN is capable of serving as an applicable marker for later osteogenic differentiation [6]. Previous studies have also suggested that the level of OPN in serum and various tissues has a significant role in predicting the outcome of clinical therapy in CRC [7, 8]. OPN can bind to 2 receptor families: integrin receptors and CD44 receptors. Integrin receptors comprise an $\alpha$-subunit and a $\beta$-subunit, which can give rise to numerous subtypes (e.g., $\alpha v \beta 3, \alpha v \beta 1, \alpha v \beta 5, \alpha v \beta 6$, $\alpha 8 \beta 1$, and $\alpha 5 \beta 1$ ) that bind with Arginine-Glycine-Aspartate (RGD) sequences in proteins. In addition, there are other integrin subtypes (e.g., $\alpha 4 \beta 1, \alpha 9 \beta 1$, and $\alpha 4 \beta 7$ ) that can bind to the Serine-Valine-Valine-Tyrosine-Glutamic-Leucine-Arginine (SVVYGL) sequences on OPN [9-11]. Receptors on the cell surface can integrate with OPN and then induce multiple signal transfer pathways and gene expression, and can alter the basic activity of tumor cells, including metastasis, invasion, and apoptosis [12-14]. However, the exact mechanisms of how OPN contributes to CRC cell progression and autophagy remain unclear.

Autophagy, a conserved catabolic process of self-digestion in eukaryotic organism, is involved in the degeneration of organelles and cytoplasmic proteins depending on the lysosomal machinery. Autophagy can help maintain physiological homeostasis and conserve energy by recycling sources of nutrition such as amino acid and fatty acid, thereby serving as a strategic survival system when the organism is suffering from nutrient deficiency, oxygen deprivation, or any outside stress $[15,16]$. Previous studies have indicated that autophagy is associated with the pathogenesis of multiple diseases such as infections, cardiovascular and pulmonary metabolic disorders, neurodegenerative diseases, and cancers, including CRC [17-20]. The process of autophagy involves complex autophagy regulating pathways. RGD, CD44, p38 MAPK, and Erk1/2 are among the familiar signaling pathways thought to be involved in cell autophagy $[21,22]$. Survival factors, growth factors, and cytokines can activate upstream pathways like MAPK or Erk1/2 that could, in turn, regulate the mTOR pathway [23].

Up to now, connections between OPN, autophagy, and colorectal cancer have not been reported. In the present study, we therefore analyzed the role of OPN in the proliferation, invasion, and apoptosis of CRC cells, and investigated the relationship between OPN and autophagy, seeking to clarify the complex mechanisms involved in regulating CRC cell autophagy by OPN. 


\section{Cellular Physiology Cell Physiol Biochem 2017;41:1851-1864 \begin{tabular}{c|l|l}
\hline DOI: 10.1159/000471933 & (c) 2017 The Author(s). Published by S. Karger AG, Basel
\end{tabular} and Biochemistry \\ Huang et al.: Osteopontin Inhibits Apoptosis and Autophagy in Colorectal Cancer}

\section{Materials and Methods}

Reagents and experiments design

Human colorectal cancer cell line HCT116 was acquired from Culture Collection of the Chinese Academy of Sciences, Shanghai, China. Roswell Park Memorial Institute 1640 was purchased from Gibco. Cell counting kit-8, transwell chamber assay, flow cytometry for assay were purchased from Dojindo, Corning Costar Corp and BD Biosciences, respectively. RIPA extraction reagents and BCA protein assay kit were purchased from Pierce, and trizol reagent was purchased from Life Technology. Complementary DNA synthesis kit and SYBR Green master mix were purchased from BIO-RAD and Applied Biosystems, respectively. Recombinant OPN protein (rhOPN) was synthesized from Sigma, and OPN antibody, RGD peptide, CD44 receptor antibody, p38MAPK receptor antibody, Erk1/2 receptor antibody, primary LC3B antibody, integrin $\alpha v$ antibody, integrin $\beta 3$ antibody, BafilomycinA1, goat anti-rabbit IgG heavy and light chain/ horseradish peroxidase were purchased from Abcam. Alexa 488-coupled Goat Anti-Rabbit IgG secondary antibody was purchased from Thermo Fisher. GAPDH antibody, P62 antibody, Atg7 antibody, Beclin1 antibody, Atg4b antibody and Bnip3 antibody were purchased from Cell Signaling Technology. Vps34 antibody was purchased from Sigma Aldrich.

To analyze the role of OPN on cell progression and autophagy, HCT116 cells were designed as following groups with diverse treatments for 6h. Empty treatments were done in blank control group, and IgG control group was treated with homogenous IgG antibody; low OPN group was treated with $200 \mathrm{ng} / \mathrm{ml} \mathrm{OPN}$; high OPN group was treated with $500 \mathrm{ng} / \mathrm{ml}$ OPN; anti-OPN group was treated with $10 \mathrm{ug} / \mathrm{ml}$ specific OPN antibody; Cell proliferation, apoptosis rate, migration abilities, invasion abilities were detected CCK8 assay, flow cytometric, wound healing assay and transwell chamber assay, respectively. PCR and western blot was used to detect the expression of autophagy related genes and proteins in control, 200ng/ml OPN group and anti-OPN group. Laser confocal scanning microscopy precisely detected the formation of autophagosomes. We also treated HCT116 cells with BafilomycinA1for 6h, in addition, 200ng/ml OPN was added to monitor autophagic flux by comparing LC3-II levels at the time points $6 \mathrm{~h}, 12 \mathrm{~h}$ and $24 \mathrm{~h}$, respectively.

Moreover, for the purpose of investigating the possible signaling pathways that OPN regulates HCT116 cell autophagy, several groups were also designed for 24h. Empty treatments were done in blank control group, and IgG control group was treated with homogenous IgG antibody; OPN group was treated with 200ng/ml OPN; anti-integrin group was treated with 10ug/ml concentration of RGD peptide; anti-integrin + OPN group pretreated with $10 \mathrm{ug} / \mathrm{ml}$ concentration of RGD peptide for $30 \mathrm{~min}$, and then added with $200 \mathrm{ng} / \mathrm{ml}$ concentration of OPN; anti-CD44 group was treated with 10ug/ml concentration of specific CD44 antibody; anti-CD44 + OPN group was pretreated with $10 \mathrm{ug} / \mathrm{ml}$ concentration of specific CD44 antibody for $30 \mathrm{~min}$ and then added with 200ng/ml concentration of OPN; anti-p38 MAPK group was treated with 10ug/ $\mathrm{ml}$ concentration of specific p38 MAPK antibody; anti-p38 MAPK + OPN group was pretreated with 10ug/ $\mathrm{ml}$ concentration of specific $\mathrm{p} 38$ MAPK antibody for $30 \mathrm{~min}$ and then added with $200 \mathrm{ng} / \mathrm{ml}$ concentration of OPN; anti-Erk1/2 group was treated with $10 \mathrm{ug} / \mathrm{ml}$ concentration of specific Erk1/2 antibody; anti-Erk1/2 + OPN group was pretreated with $10 \mathrm{ug} / \mathrm{ml}$ concentration of specific Erk1/2 antibody for 30min and then added with $200 \mathrm{ng} / \mathrm{ml}$ concentration of OPN. We compared and analyzed the expression Beclin1, Atg4b, Bnip3, Vps34of at the level of transcriptional and translational, and detected the expression of protein p38MAPK and p-p38MAPK in OPN group. Then, we measured the expression of LC3-II/LC3-I, P62, Atg7 in those groups, and the formation of autophagosomes in the control, OPN, anti-p38 MAPK and anti-p38 MAPK+OPN groups.

\section{Cell culture}

HCT116 cells were generally cultured in RPMI-1640 medium supplement with $10 \%$ fetal bovine serum and $1 \%$ Penicillin-Streptomycin Solution, then the cells were maintained in an incubator at $37^{\circ} \mathrm{C}$ with humidified 5\% CO2 atmosphere. Cells harvested between passage 4 and 5 were used for the study.

\section{Cell proliferation assay}

The cells were seed into 96-well plate at the density of $3 \times 10^{3}$ cells in each well, supplied with $100 \mathrm{ul}$ RPMI-1640 medium containing 99\% RPMI-1640 and 1\% FBS. The cell proliferation viability was evaluated by the CCK8. In brief, 10ul CCK8 solution was given to each well of the plate after different incubation times: $0 \mathrm{~h}, 6 \mathrm{~h}, 12 \mathrm{~h}, 24 \mathrm{~h}$ and $48 \mathrm{~h}$. At last, we measured the absorbance at $450 \mathrm{~nm}$ wavelength after $2 \mathrm{~h}$ incubation in an incubator at $37^{\circ} \mathrm{C}$ with humidified $5 \% \mathrm{CO} 2$ atmosphere. 


\section{Cellular Physiology Cell Physiol Biochem 2017;41:1851-1864

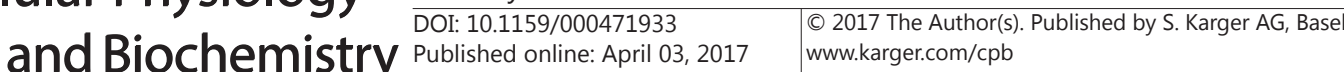

Huang et al.: Osteopontin Inhibits Apoptosis and Autophagy in Colorectal Cancer

Apoptosis detection by flow cytometry

Cell apoptosis was detected by propidium iodide and annexin-V staining in accordance with the manufacture's guidance. Cells were seed into 6-well plate at the density of $1 \times 10^{6}$ cells in each well, supplied with $2 \mathrm{ml}$ medium containing RPMI-1640. Cells were digested and washed with PBS twice, then suspended in binding buffer at the density of $2 \times 10^{5}$ cells/well. Subsequently, the cells were stained with 5 ul propidium iodide and 5 ul annexin V-fluorescein isothiocyanatye for 20 minutes in darkness, detected by FACSCalibur (BD Biosciences, USA) using a $488 \mathrm{~nm}$ argon ion laser. The lower left, lower right, upper right and upper left of the images indicated viable cells, early apoptotic cells, late apoptotic cells, and mechanically-injured cells, respectively.

\section{Wound healing assay}

Scratch wound-healing assay was used to analyze cell migration. Cells were seeded into 6-well culture plates at $5 \times 10^{5}$ cells/well in RPMI-1640 medium and cultured in an incubator. We used a sterile micropipette tip to scratch the confluent monolayers in the shape of a straight line, and washed floating cells with PBS three times. Wound healing was performed by treatment with OPN or specific OPN antibody in accordance with the treatment methods. The cells were allowed to cover the wound for $24 \mathrm{~h}$. Pictures of the same wound position were taken at the time of scratching and after $24 \mathrm{~h}$ under a microscope. The migration results were tested by Image J software.

\section{Cell invasion assay}

The ability of the cell to pass though the matrigelcoated filters was detected by transwell chamber invasion assay. The transwell chamber assays were designed utilizing $8 \mathrm{um}$ pore and $6.5 \mathrm{~mm}$ polycarbonate transwell filters. The cells were trypsinizated, suspended and seeded in the upper chamber at a final concentration of $2.5 \times 10^{5}$ cells $/ \mathrm{ml}$ in RPMI-1640 medium without serum. Subsequently, the medium containing 90\% RPMI-1640 supplement with 10\% FBS was added to the bottom chamber of the chamber as a chemo-attractant. Eventually, the chamber was maintained in an incubator at $37^{\circ} \mathrm{C}$ with humidified $5 \%$ CO2 atmosphere. After incubation for $36 \mathrm{~h}$, the chamber was fixed by $4 \%$ paraformaldehyde for $30 \mathrm{~min}$ and then stained by $0.1 \%$ crystal violet for 30 minutes in a biosafety cabinet which was away from light at room temperature. The cells on the surface of matrigel without invading ability of upper chamber were removed by scraping. At last, we used a magnification microscope to count the amount of the invasion cells in the bottom of the chamber.

\section{Protein extraction and Western-blotting}

Total protein of the cells in each group was extracted using RIPA extraction reagents with $1 \%$ phenylmethanesulfonyl fluoride (PMSF) and 1\% DL-Dithiothreitol (DTT). The concentration of the lysate protein was detected by a BCA protein assay kit. Equal amount of $20 \mathrm{ug}$ protein in each group was separated by $12 \%$ sodium dodecyly sulfate-polyacrylamide gel electrophoresis (SDS-PAGE), and then the protein in the gel were transferred onto polyvinylidene difluoride membranes (PVDF). Subsequently, the PVDF membranes were blocked with 5\% non-fat dry milk dissolved in TBST buffer (20mM Tris-Hcl, $150 \mathrm{mM} \mathrm{NaCl}$, $0.1 \%$ Tween 20 , PH 7.40 ) in $25^{\circ} \mathrm{C}$ room temperature for about $1 \mathrm{~h}$, and then washed for three times in TBST, each time for $15 \mathrm{~min}$. In addition, the membranes were incubated with primary antibodies at $4^{\circ} \mathrm{C}$ for $12 \mathrm{~h}$ (anti-LC3B, 1:1000; anti-integrin $\alpha v, 1: 500$; anti-integrin $\beta 3$; anti-CD44, 1:5000; anti-p38 MAPK, 1:500; anti-p-p38 MAPK, 1:1000; anti-Erk1/2, 1:2000; anti-p-Erk1/2, 1:500 ). Afterwards, the membranes were washed in TBST three times, each for $15 \mathrm{~min}$, and then incubated with goat anti-rabbit IgG heavy and light chain/ horseradish peroxidase at $25^{\circ} \mathrm{C}$ room temperature for $1 \mathrm{~h}$. GAPDH was used as a loading control and normalization (anti-GAPDH, 1:1000). The result of western blotting was measured using Omega Lum G (aplegen, USA) and the bands were quantified using Imaging J analysis software.

RNA exaction, cDNA synthesis and reverse transcription-polymerase chain reaction (RT-PCR) analysis

The 500ng total RNA, including mRNA, of the cells in each group was isolated using trizol reagent in accordance with the guidance of the manufacturer. $1 \mathrm{ml}$ trizol reagent was added to homogenize the cells in 6-well plate, and the lysates pipetted to $1.5 \mathrm{ml}$ centrifuge cube and incubated for 5 minutes. Following, 200ul trichloromethane per $1 \mathrm{ml}$ trizol reagent used was added to the tube, and this tube was shaken vigorously by hand for 20 seconds. After 2 minutes of incubation, the selected sample was centrifuged at 12,000 x $\mathrm{g}$ 


\section{Cellular Physiology Cell Physiol Biochem 2017;41:1851-1864

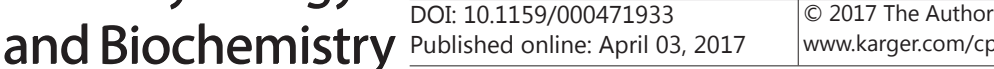 \\ Huang et al.: Osteopontin Inhibits Apoptosis and Autophagy in Colorectal Cancer}

for 15 minutes at $4^{\circ} \mathrm{C}$. The supernatant liquor of the tube was transferred to a new sterile tube and $1 \mathrm{ml}$ anhydrous ethanol once and $1 \mathrm{ml} \mathrm{80 \%} \mathrm{anhydrous} \mathrm{ethanol} \mathrm{with} \mathrm{20 \%} \mathrm{DEPC} \mathrm{water,} \mathrm{added} \mathrm{twice,} \mathrm{were} \mathrm{thence}$ mixed. Subsequently, the mixture was centrifuged at $12,000 \mathrm{x}$ g for 5 minutes at $4^{\circ} \mathrm{C}$. The supernatant liquor was suctioned out, and a small white fragment was observed. At last, 20ul RNase-free water was added to the tube and incubated for 1 minute.

A total volume of $20 \mu \mathrm{l}$, including $15 \mu \mathrm{l}(1 \mu \mathrm{g})$ RNA template and nuclease-fee water, $4 \mu \mathrm{l} 5 \mathrm{x}$ PrimeScript $^{\mathrm{TM}}$ reaction mix, and $1 \mu \mathrm{l}$ iScript reverse transcriptase in each group was used to generate the first strand by utilizing the First Strand cDNA Synthesis Kit, according to the manufacturer's instructions. Subsequently, a $10 \mu \mathrm{l}$ mixture of RT-PCR was prepared in each well of the plate, containing $5.5 \mu \mathrm{l}$ of buffer with SYBR Green, $4.5 \mu \mathrm{l}$ nuclease-free water, and the cDNA sample. Next, the conditioning process of RTPCR was performed by a thermal cycle as follows: $95^{\circ} \mathrm{C}$ for $10 \mathrm{~min}, 45$ cycles at $95^{\circ} \mathrm{C}$ for $15 \mathrm{~s}$, and $59^{\circ} \mathrm{C}$ for $1 \mathrm{~min}$. During the process, we also added a no RT transcript control to the 96 -well plate for each gene to make sure that the signal was actually driven by the target gene amplification. The prime sequences were as follows. Atg4b-forward: 5'-AGAGCCCGTTTGGATACT-3', Atg4b-reverse: 5'-GTCGATGAATGCGTTGAG-3'; Beclin1-forward: 5'-CAAGATCCTGGACCGTGTCA-3', Beclin1-reverse: 5'-TGGCACTTTCTGTGGACATCA-3'; Bnip3-forward: 5'-TCCACTTCAGACACCCTA-3', Bnip3-reverse: 5'-CTCAGTCGCTTTCCAATA-3'; VPS34forward: 5'-GGACCTTCTGACCACGAT-3', VPS34-reverse: 5'-GCAACAGCATAACGCCTC-3'; GAPDH-forward: 5'-GACCCCTTCATTGACCTC-3', GAPDH-reverse: 5'-GCTAAGCAGTTGGTGGTG-3'. The expression level of the target mRNA was normalized by the expression of GAPDH. The collected data were quantified using the $\Delta \Delta$ Ct method.

\section{Immunofluorescence and laser confocal detection}

Coverslips were laid flat on the bottom of a 6-well plate after cleaning, disinfection, and 24-h ultraviolet irradiation. Next, the cells were seeded on the coverslips at a density of $1 \times 10^{6}$ in each well, cultured in an incubator. The coverslips were rinsed with PBS for 5 min 3 times and fixed with $4 \%$ paraformaldehyde for $15 \mathrm{~min}$, followed by permeabilization of the cells in $0.2 \%$ TritonX-100 for another $20 \mathrm{~min}$. Next, the coverslips were rinsed with PBS again for 5 min 3 times and blocked by incubating the HCt116-attached cells in 5\% BSA for 60 min. Then, the cells were stained with a rabbit anti-human LC3B antibody, followed by a 12 -hour incubation period at $4^{\circ} \mathrm{C}$. After washing the uncombined antibody with PBS for 5 min 3 times, the cells were incubated with Alexa 488-coupled Goat Anti-Rabbit IgG secondary antibody for $1 \mathrm{~h}$ at $4^{\circ} \mathrm{C}$ in the darkness. Finally, DAPI was used as a counterstain to label the nuclei. The stained HCT116-attached cells were then acquired and photographed with a fluorescent microscope and laser confocal microscopy.

Statistical analysis

The experiments in this article were performed in triplicate, and the data were expressed as means \pm SEM. Statistical analysis of the data from 2 groups was performed using the Student $t$-test or one-way ANOVA. $\mathrm{P}<0.05$ was considered to be significant.

\section{Results}

OPN promotes HCT116 cell proliferation and inhibits cell apoptosis

We first investigated the role of OPN in the proliferation of HCT116 cells, and used 2 different concentrations of OPN-treated cells, and the results showed that OPN can promote cell proliferation in vitro. In addition, OPN-specific antibody can reduce cell proliferation, as is demonstrated in the proliferation assay (Fig. 1A).

Next, we studied the effects of OPN on the apoptosis of HCT116 cells using flow cytometry, and found that apoptotic cells in the HCT116 cell line were increased in the antiOPN group and decreased in the OPN groups, as reflected by an increase in the proportion of total annexin-V-positive staining cells. Higher levels of OPN seemed to have the tendency to decrease the proportion of apoptotic annexin-V-positive cells, which further demonstrated that OPN inhibits cell apoptosis in vitro (Fig. 1B, C). However, OPN seemed to have no effect on the early apoptotic cells, which were assessed by propidium iodide-negative staining and annexin-V-positive staining, as the results were not statistically significant (Fig. 1D). The late 


\section{Cellular Physiology Cell Physiol Biochem 2017;41:1851-1864 \begin{tabular}{l|l|l} 
DOI: 10.1159/000471933 & $\begin{array}{l}\text { () } 2017 \text { The Author(s). Published by S. Karger AG, Basel } \\
\text { www.karger.com/cpb }\end{array}$
\end{tabular}

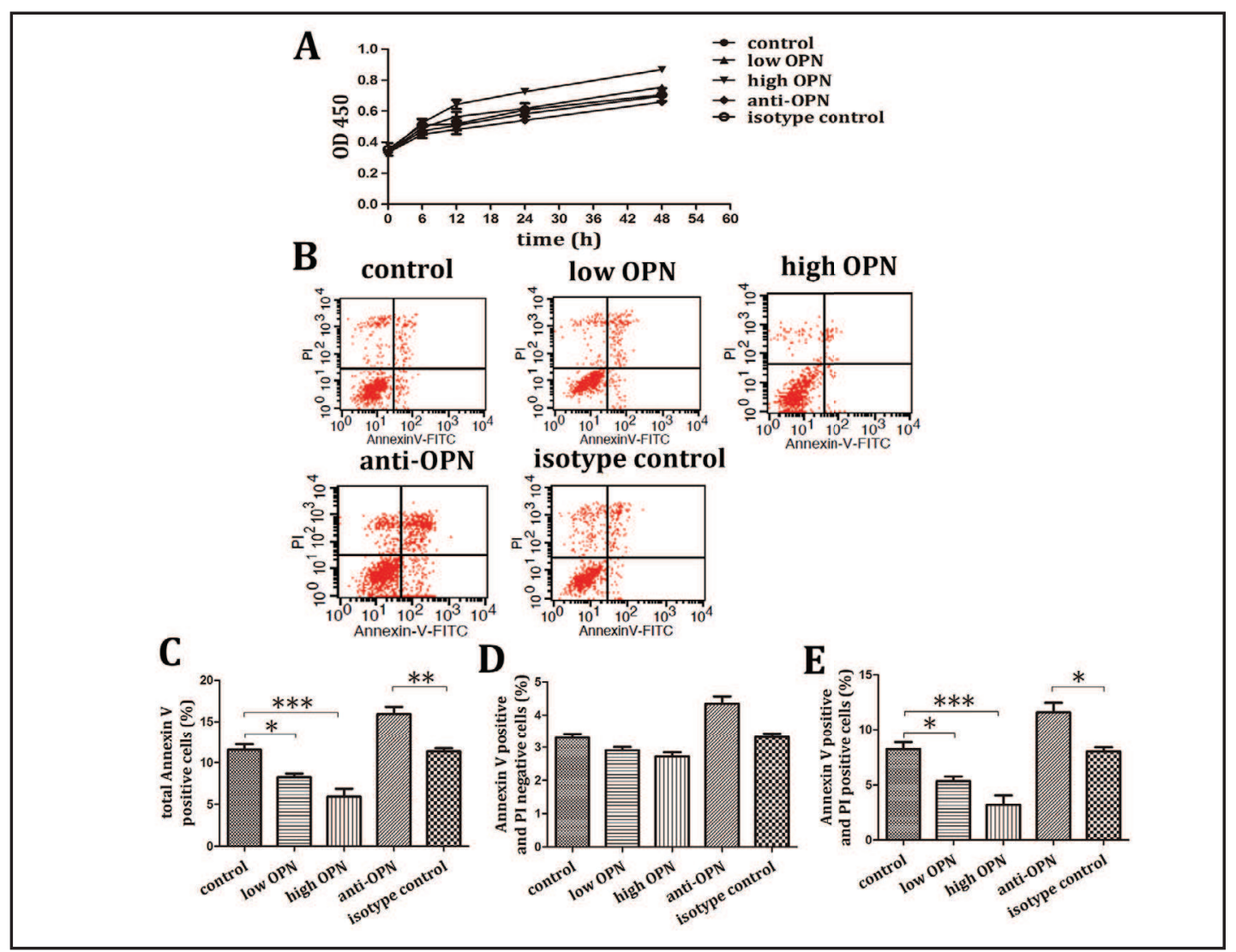

Fig. 1. OPN promotes HCT116 cell proliferation and inhibits cell apoptosis. (A) The $450 \mathrm{~nm}$ OD in 6 groups at the $0 \mathrm{~h}, 6 \mathrm{~h}, 12 \mathrm{~h}, 24 \mathrm{~h}$, and $48 \mathrm{~h}$ time points were tested by CCK- 8 cell proliferation and activity detection kit. (B) Apoptosis rates were determined by flow cytometric analysis with annexin-V/PI double-staining. (C) Total percentage of annexin-V-positive cells of OPN groups were lower compared with the control, while the rate of the anti-OPN group was higher than that of the isotype control. (D) The percentage of Annexin-V-positive and PI-negative cells (early apoptosis) showed no significantly difference in the OPN groups and the anti-OPN group compared with the control and the isotype control, respectively. (E) The percentage of Annexin-V-positive and PI-positive cells (late apoptosis) in the OPN groups was lower than that of the control, while in the anti-OPN group it was higher compared with the isotype control. All group values are given as mean \pm SEM. $* \mathrm{P}<0.05,{ }^{* *} \mathrm{P}<0.01$ and ${ }^{* * *} \mathrm{P}<0.001$.

apoptotic cells were reduced in the OPN groups and increased in the anti-OPN group, as reflected by a decrease in the percentage of propidium iodide-positive staining and annexinV-positive staining cells (Fig. 1E).

\section{OPN promotes HCT116 cell migration and invasion}

To confirm that OPN is an important factor for HCT116 cell migration and invasion, we examined the migration and invasion ability of the cells by wound healing and transwell invasion assay. Cell migration (Fig. 2A, B) and invasion (Fig. 2C, D) were increased in OPN groups compared with the control, and the high-OPN group tended to have stronger biological capability. Moreover, using OPN-specific antibody could reduce the observed cell migration and invasion ability.

OPN inhibits HCT116 cell autophagy

The expressions of Beclin1, Atg4b, Bnip3, and Vps34 were downregulated at both the mRNA (Fig. 3A) and protein levels (Fig. 3B, C) in the low-OPN or high-OPN groups compared with the control, while treatment with specific OPN antibodies could upregulate 


\section{Cellular Physiology Cell Physiol Biochem 2017;41:1851-1864 and Biochemistry DOI: 10.1159/000471933 2017 O 2017 The Author(s). Published by S. Karger AG, Basel}
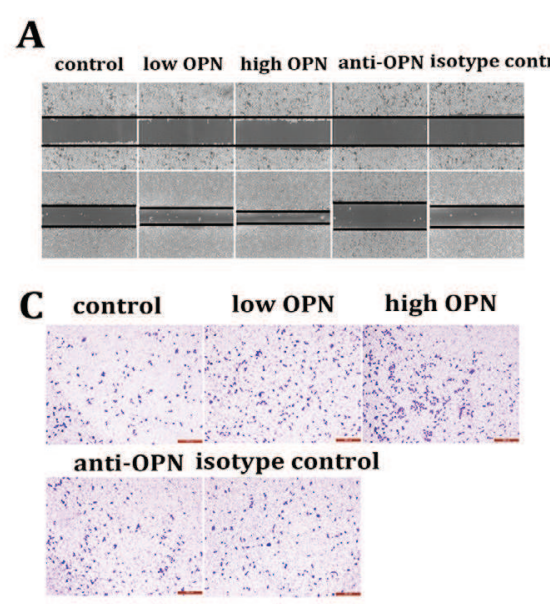

$\mathbf{B}_{200}$
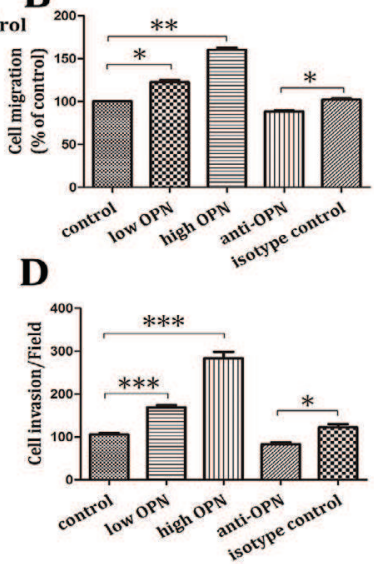

Fig. 2. OPN promotes HCT 116 cell migration and invasion. (A and B) Migration abilities of cells were determined by wound healing assay at the $\mathrm{o}$ h and $24 \mathrm{~h}$ time points (image magnification, $\times 100$ ). (C and D) Invasion abilities of cells were detected by transwell chamber assay (image magnification, $\times 200$ ); OPN could promote cell migration and invasion, as the results shown are statistically significant between the OPN groups and the control or between the anti-OPN group and the isotype control. All group values are given as mean \pm SEM. $*$ P $<0.05,{ }^{* *} \mathrm{P}<0.01$, and ${ }^{* * *} \mathrm{P}<0.001$.

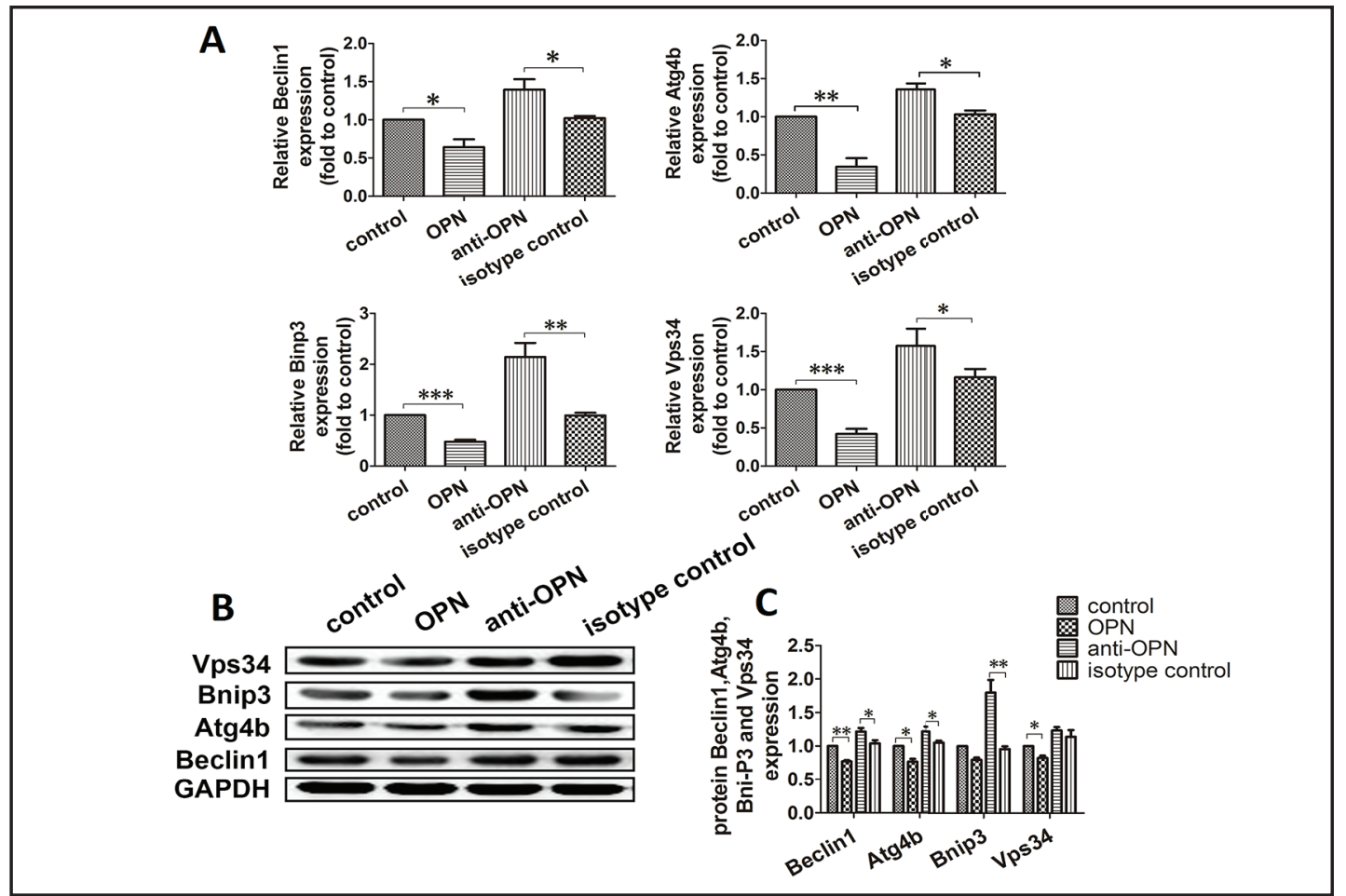

Fig. 3. OPN inhibits autophagy in HCT116 cells. (A) RT-PCR was used to measure the expression of autophagy-related genes, including Beclin1, Atg4b, Binp3, and Vps34 in the control, OPN, anti-OPN group and isotype control groups. The expressions of 4 genes were lower in the OPN group and higher in anti-OPN group compared with the control and isotype control, respectively. (B) Western blot analysis was applied to detect the expression levels of the 4 proteins, and GAPDH was used as a normalization control. (C) The results showing the expressions of Beclin1, Atg4b, Bnip3, and Vps34 in the OPN group were lower compared with the control, while the results in the anti-OPN group were the exact opposite compared with the isotype control. All group values are given as mean \pm SEM. ${ }^{*} \mathrm{P}<0.05$, ${ }^{* *} \mathrm{P}<0.01$, and ${ }^{* * *} \mathrm{P}<0.001$. 


\section{Cellular Physiology Cell Physiol Biochem 2017;41:1851-1864 \begin{tabular}{c|l|l} 
aOI: 10.1159/000471933 & ( 2017 The Author(s). Published by S. Karger AG, Basel
\end{tabular} \\ Huang et al.: Osteopontin Inhibits Apoptosis and Autophagy in Colorectal Cancer}

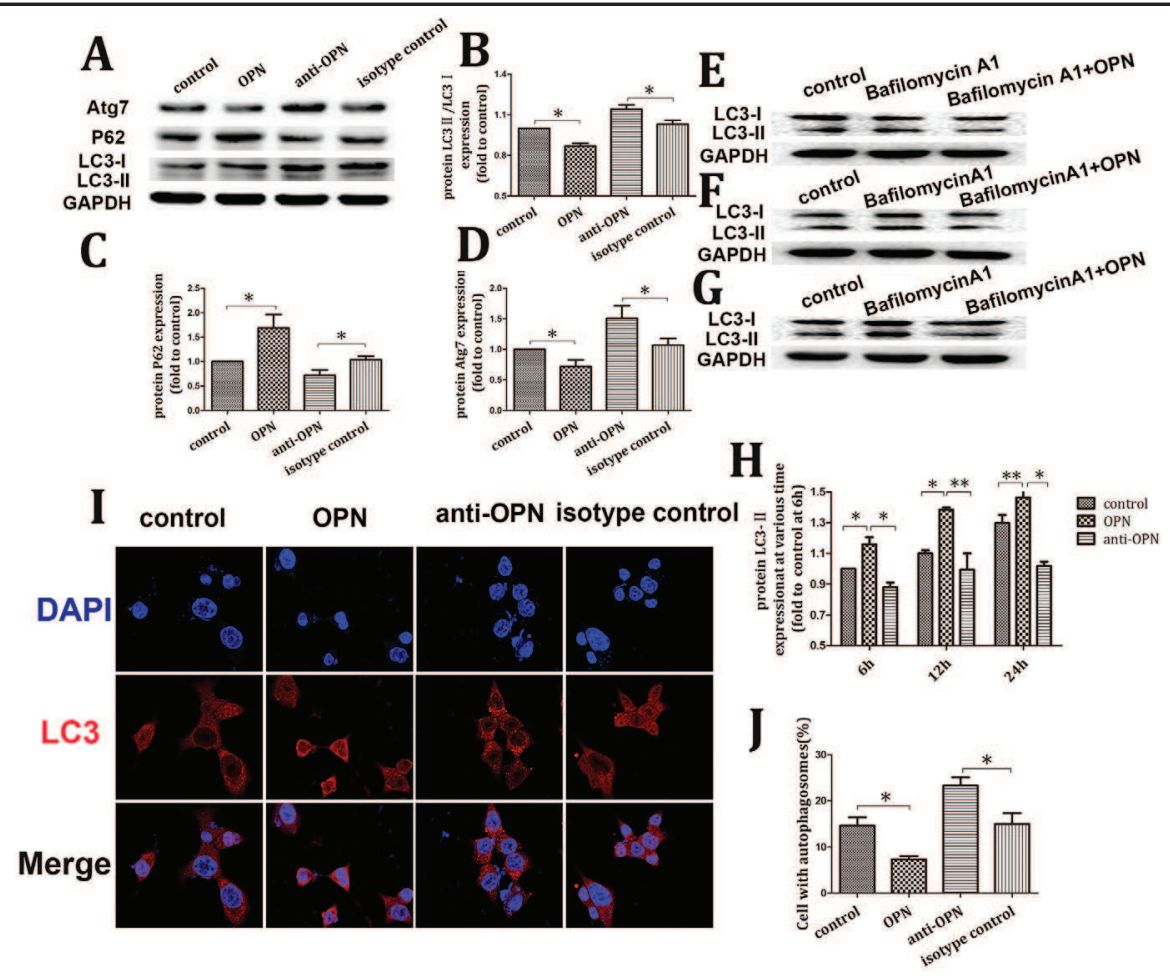

Fig. 4. OPN inhibits autophagy in HCT116 cells. Representative Western blots (A) and quantitative analysis of LC3-II/LC3-I (B), P62 (C), and Atg7 (D) protein expression were measured in control, OPN, anti-OPN group and isotype control groups. The expression levels of LC3-II/LC3-I was increased when HCT116 cells were treated with Bafilomycin A1 at $6 \mathrm{~h} \mathrm{(E),} 12 \mathrm{~h}(\mathrm{~F})$ and $24 \mathrm{~h}$ time points (G), while these effects could be significantly reversed by OPN. (H) Semiquantitative analysis of the expression of LC3-II/LC3-I was arranged. (I and J) Representative confocal microscopic image showing the increased enhancement expression of autophagosomes in anti-OPN group and weaken expression of autophagosomes in OPN group compared with the isotype control and the control, respectively, (image magnification, $\times 600$ ). All group values are given as mean \pm SEM. $* \mathrm{P}<0.05$ and ${ }^{* *} \mathrm{P}<0.01$.

the expression of autophagy-related genes. Expression levels of proteins LC3-II/LC3-I (Fig. 4A, B) and Atg7 (Fig. 4A, D) were increased by OPN inhibition, which was demonstrated by Western-blot analysis, and the higher-OPN group seemed to have lower protein expression levels compared with the low-OPN or the control group. Similarly, expression levels of the protein P62 were significantly increased in the OPN group (Fig. 4A, C).

Positive signals in immunofluorescence were qualified as previous described [24]. It was found that the OPN group could decrease and the anti-OPN group could increase the formation of autophagosomes compared with the control group and the isotype control group, respectively, as demonstrated by immunofluorescence and co-focusing experimental analysis (Fig. 4I, J).

To further confirm that OPN has an important role in the autophagic flux, we performed some experiments to measure the amount of LC3-II delivered to lysosomes by comparing LC3-II levels treated with Bafilomycin A1 and Bafilomycin A1 + OPN at various time points. The results show that blockage of lysosomal degradation by Bafilomycin A1 could enhance the amount of LC3-II, and that OPN reversed the amount of LC3-II induced by Bafilomycin A1 (Fig. 4E, F, G, H).

\section{OPN inhibits cell autophagy through the $p 38$ MAPK signaling pathway}

The protein expression levels of p38 MAPK and p-p38 MAPK in HCT 116 cells were increased in the OPN group compared with the control (Fig. 5D), while protein levels of 


\section{Cellular Physiology Cell Physiol Biochem 2017;41:1851-1864 and Biochemistry DOI: 10.1159/000471933 $\quad$ O 2017 The Author(s). Published by S. Karger AG, Basel

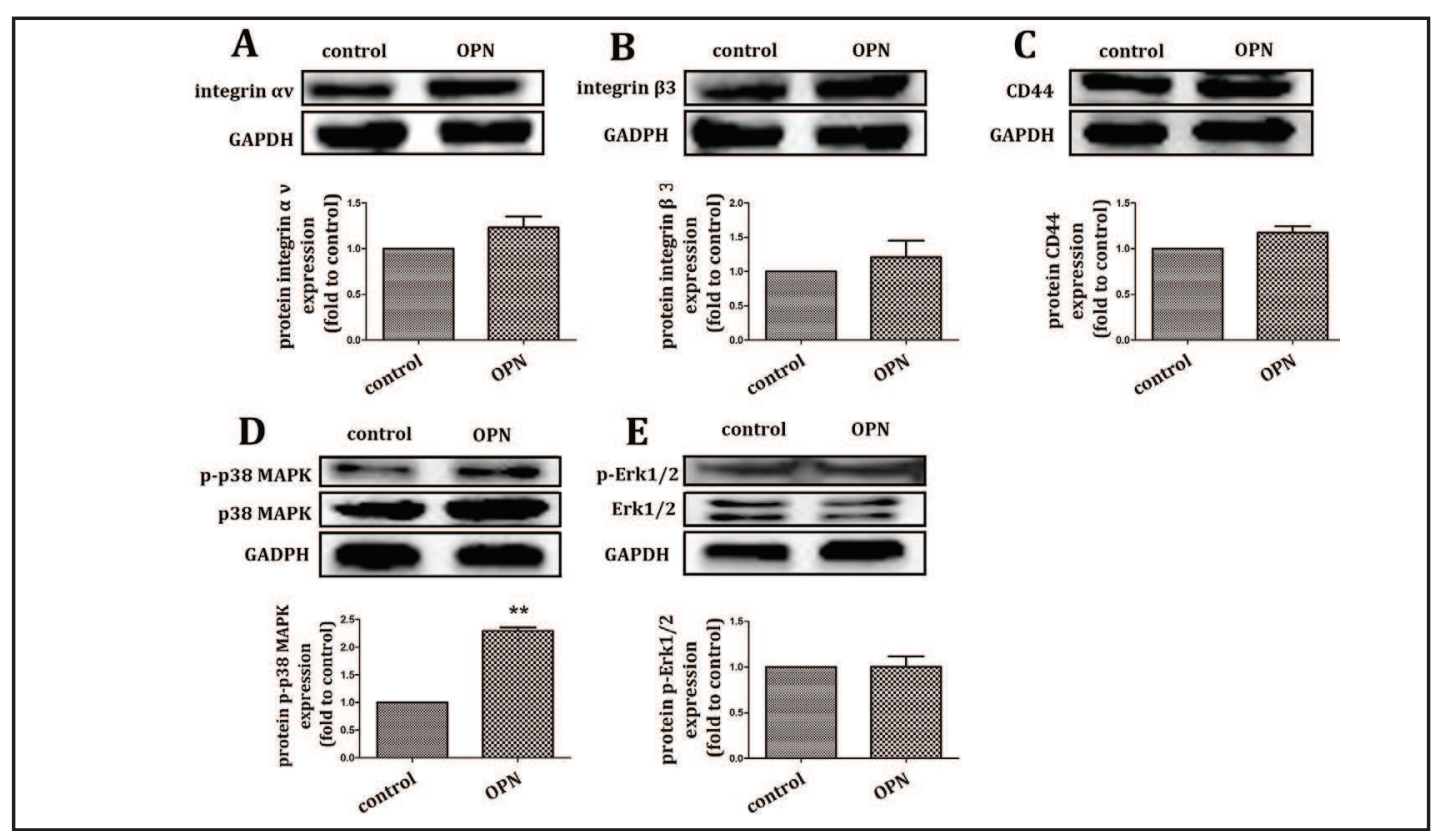

Fig. 5. OPN promotes the expression of protein p38 MAPK. Relative expressions of protein integrin $\alpha v(A)$, integrin $\beta 3$ (B), CD44 (C), p38 MAPK, p-p 38 MAPK (D), Erk1/2, and p-Erk1/2 (E) were measured by Western blot analysis. GAPDH was used as a normalization control. All group values are given as mean \pm SEM. **P $<0.01$.
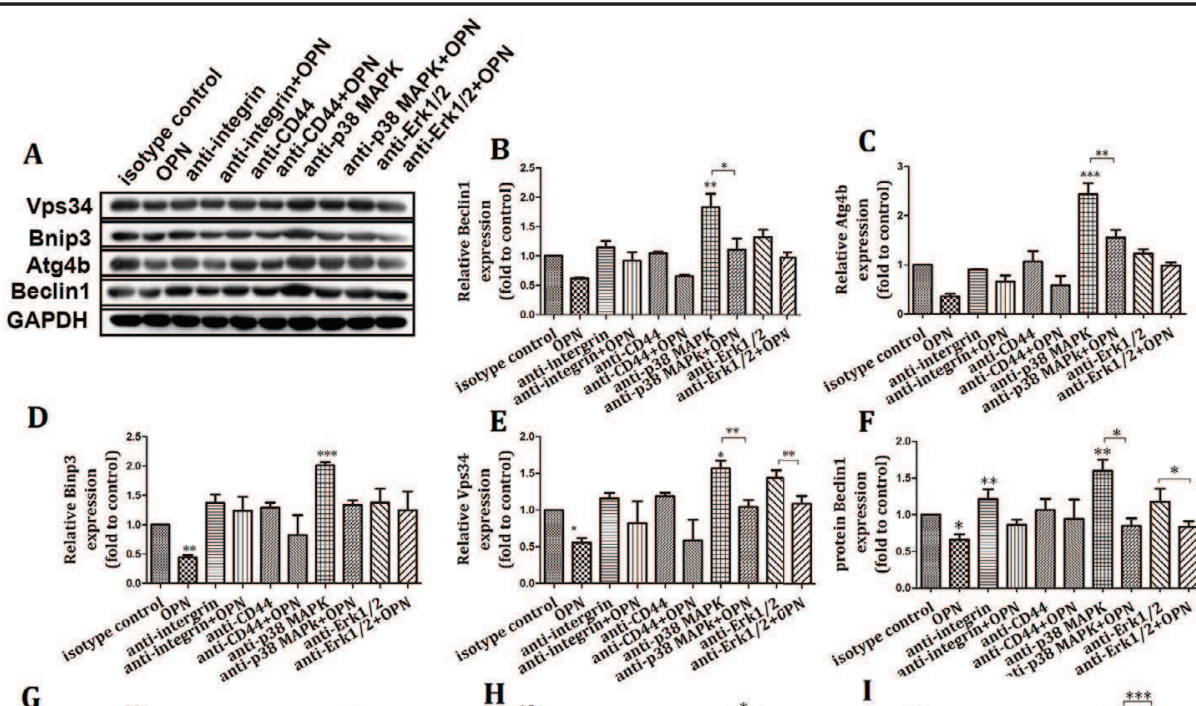

G
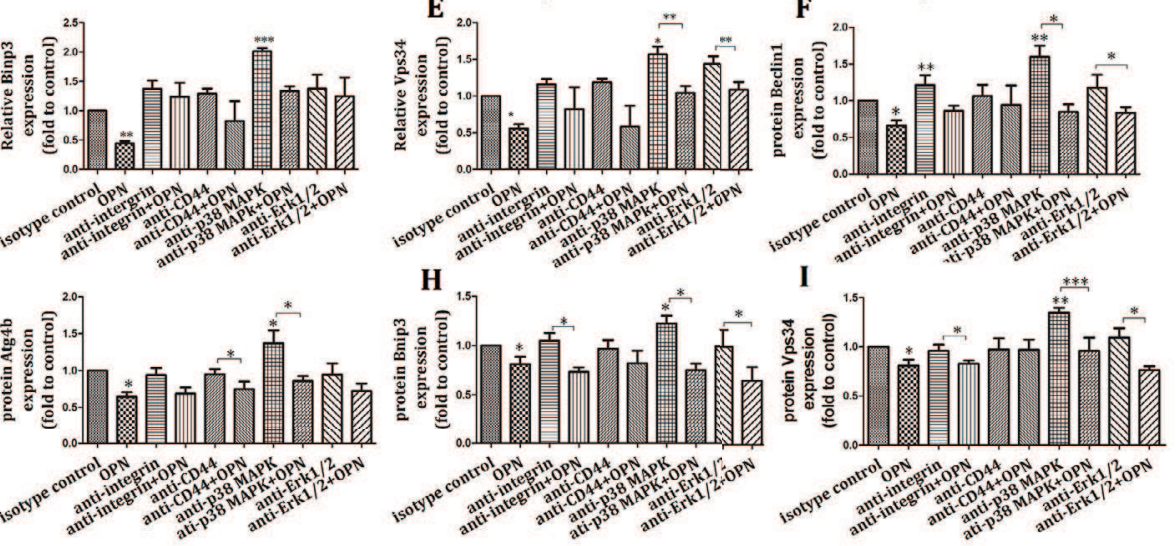

Fig. 6. Expression of the autophagy-related genes and the proteins were higher in the anti-p38 MAPK group. RT-PCR was used to measure the expression of autophagy-related genes Beclin1 (B), Atg4b (C), Binp3 (D), and Vps34 (E) of HCT 116 cells in 10 groups. Western blot analysis (A) was applied to detect Beclin1 (F), Atg4b (G), Binp3 (H), and Vps34 (I) protein levels. GAPDH was used as a normalization control. All group values are given as mean $\pm \mathrm{SEM}$. ${ }^{*} \mathrm{P}<0.05,{ }^{* *} \mathrm{P}<0.01$ and ${ }^{* * *} \mathrm{P}<0.001$. 


\section{Cellular Physiology Cell Physiol Biochem 2017;41:1851-1864

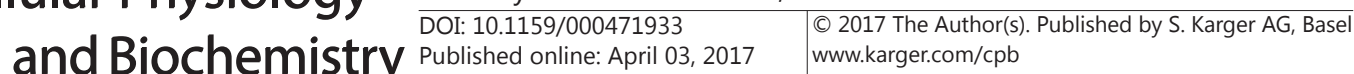 \\ Huang et al.: Osteopontin Inhibits Apoptosis and Autophagy in Colorectal Cancer}

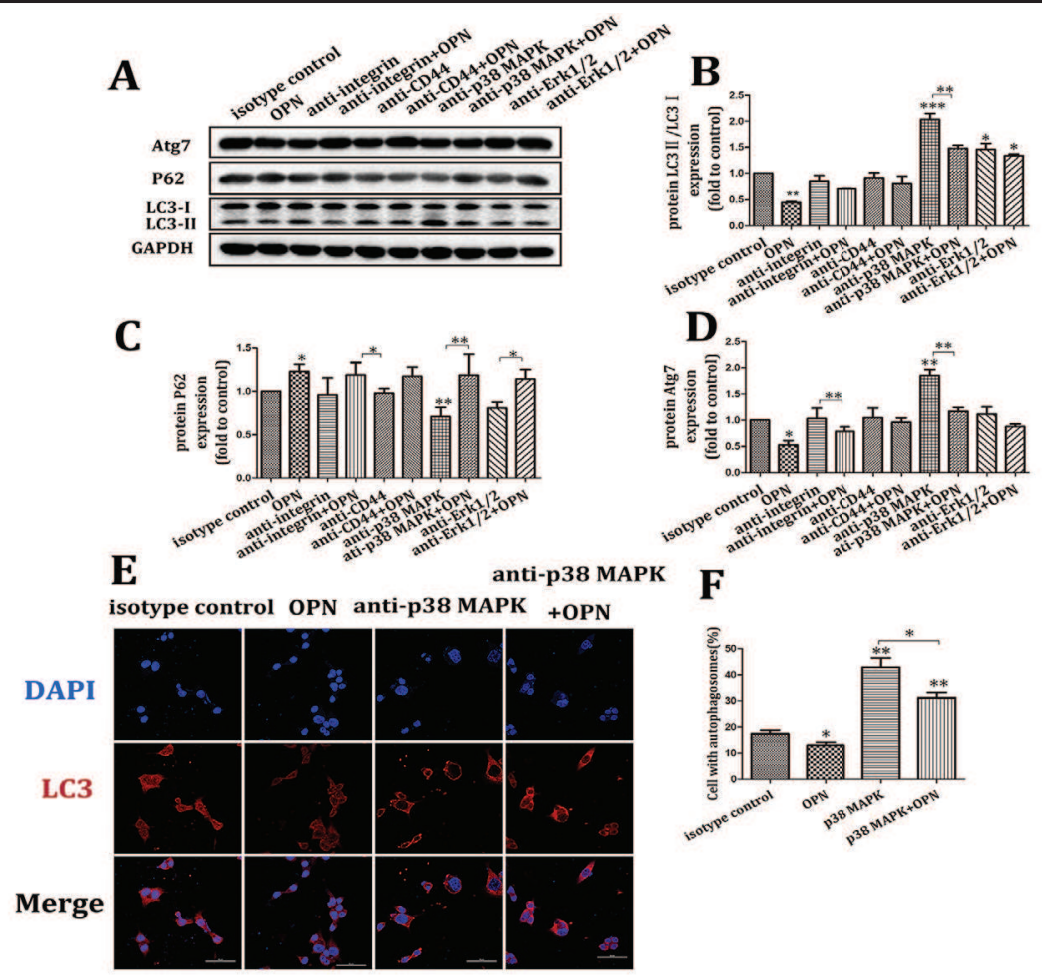

Fig. 7. OPN inhibits autophagy via the p38 MAPK pathway. Representative Western blots (A) and quantitative analysis of LC3-II/LC3-I (B), P62 (C), and Atg7 (D) protein expressions were detected in 10 groups, the expressions of LC3-II/LC3-I and Atg7 were higher in the p38 MAPK group compared with the isotype control, while protein P62 was less expressed in the p38 MAPK group compared with the isotype control. (E and F) Representative confocal microscopic image showing the enhanced expression of autophagosomes in the anti-p38 MAPK group compared with the isotype control or the anti-p38 MAPK+OPN group, (image magnification, $\times 600$ ). All group values are given as mean $\pm \mathrm{SEM}$. ${ }^{*} \mathrm{P}<0.05,{ }^{* *} \mathrm{P}<0.01$ and ${ }^{* * *} \mathrm{P}<0.001$.

integrin $\alpha v \beta 3$, CD44, Erk1/2, and p-Erk1/2 were not significantly different in expression compared with the control (Fig. 5A, B, C, E). Expressions of Beclin1, Atg4b, Bnip3, and Vps34 were upregulated at both mRNA (Fig. 6B, C, D, E) and protein levels (Fig. 6A, F, G, H, I) in the anti-MAPK group compared with the isotype control group, while there was no statistically significant difference between the groups in anti-CD44, anti-integrin, and anti-Erk1/2 levels. Western-blot analysis also demonstrated that proteins LC3-II/LC3-I (Fig. 7A, B), and Atg7 (Fig. 7A, D) were excessively expressed, while protein P62 (Fig. 7A, C) showed decreased expression in the anti-MAPK group.

By measuring the quantity of autophagosomes, which were detected by Laser confocal scanning microscopy, we found that the formation of autophagosomes was increased in the anti-MAPK group compared with any other group (Fig. 7E, F). Our study has demonstrated that OPN could inhibit HCT116 cell autophagy, and that this effect could be reversed by inhibiting the p38 MAPK signaling pathway. These results suggest that OPN might inhibit HCT116 cell autophagy through the p38 MAPK signaling pathway.

\section{Discussion}

In recent decades, the role of OPN in tumor progression has been widely investigated. Many previous studies from our team and others have demonstrated that the expression of OPN is higher in patients with cancer $[9,25,26]$. In addition, we have found convincing evidence that OPN is secreted by several CRC cells, including HCT116, SW480, and the 


\section{Cellular Physiology Cell Physiol Biochem 2017;41:1851-1864 and Biochemistry Publisned online: April U3, $2017 \quad \begin{aligned} & \text { D 2017 The Author(s) } \\ & \text { www.karger.com/cpb }\end{aligned}$ \\ Huang et al.: Osteopontin Inhibits Apoptosis and Autophagy in Colorectal Cancer}

secreted OPN promotes cancer cell progression in vitro. Furthermore, the secretory OPN levels of 2 metastatic cell lines, SW620 and HCT116, and 2 non-metastatic cell lines, DLD1 and SW480, were investigated, the OPN level of the SW620 and HCT116 cell lines were found to approximate a concentration of $300 \mathrm{ng}$ per $\mathrm{ml}$ [8]. A recent study of uterine endometrial carcinoma showed that exogenous OPN was capable of promoting tumor cells invasion, migration, and epithelial-mesenchymal transition (EMT) [27]. To evaluate the possible roles of extracellular OPN, our team used OPN-specific antibody to block the secreted OPN by HCT116 cells for the purpose of analyzing the influence of autocrine OPN. Recombinant human OPN was added to analyze the exogenous OPN. In our study, we compared the blank control group and the OPN groups to confirm that exogenous OPN does have effects on cell progression and autophagy. At the same time, comparing the IgG control group with the anti-OPN group allowed us to demonstrate that endocrine OPN had effects as well. We had compared the control and isotype type IgG control, and no significance was found in the two groups. Previous studies have indicated that OPN can regulate smooth muscle cell autophagy at $6 \mathrm{~h}$, and our studies found that OPN could also regulate HCT116 cell autophagy at $6 \mathrm{~h}$ [28]. We treated HCT116 cells with BafilomycinA1 in addition to OPN treatment to monitor autophagic flux at $6 \mathrm{~h}, 12 \mathrm{~h}$, and $24 \mathrm{~h}$, and OPN could inhibit cell autophagy at $6 \mathrm{~h}$ to $24 \mathrm{~h}$. OPN could also significantly inhibit HCT116 cell autophagy at $6 \mathrm{~h}$.

Our study showed that OPN can promote CRC cell proliferation and inhibit cell apoptosis in vitro. We subsequently demonstrated that OPN could also facilitate cell migration and invasion in vitro as well. In our experiment, we found that OPN-specific antibody can decrease the effects induced by OPN; thus, as a tumor-related factor, OPN can promote tumor progression. Next, we demonstrated that OPN can regulate CRC cell autophagy at the level of transcription and translation. OPN can inhibit the expression of autophagy-related genes and proteins including Beclin1, Atg4b, Binp3, and vps34 and can also lower the ratio of LC3II/LC3-I. Finally, we studied the possible signaling pathways, such as the RGD-mediated, CD44-mediated, P38 MAPK-mediated, and Erk1/2-mediated pathways that OPN may rely on to affect HCT116 cell autophagy. Treatment of HCT116 cells with OPN inhibited autophagyrelated genes and protein expression. However, these effects could be reversed by blocking the p38 MAPK signaling pathway.

Despite recent developments in the in-depth understanding of and advanced therapeutic methods for CRC, the disease still has a high mortality rate. A better understanding of tumor characteristics like invasiveness and transferability, as well as the mechanisms involved in tumorigenesis, may help us develop effective therapeutic approaches that have specific molecular targets for the treatment of patients with CRC.

OPN is a phosphorylated and tumor-related protein encoded by Spp1. OPN was detected with considerable polymorphism, recent study found that the $-443 \mathrm{C}>\mathrm{T}$ polymorphism of OPN was able to serve for susceptibility as well as chemotherapy response of AML [29]. OPN is thought to contain bioactive regions on its surface, along with its RGD sequences, that can exhibit multiple biological functions, including the activation of some regulatory and structural proteins when connecting with its integrin receptors [30, 31]. CD44 receptors are sulfated adhesion glycoproteins, which can participate in the interaction, adhesion, and migration of cells [32]. Previous studies have indicated that OPN relies on CD44 receptors to activate mammalian fibroblast cells [33]. CD44 receptors are also expressed in acinic cell adenocarcinoma of salivary gland origin and mucoepidermoid carcinoma, as reported in the literature [34]. P38 MAPKs, members of the MAPK family, are activated by many environmental stresses and inflammatory cytokines. Previous research has shown that P38 MAPK signaling pathways are correlated with autophagy in CRC, and that p38 MAPK signaling promotes the expression of the mTOR signal, which can inhibit ULK-Atg13-FIP200 complexes during the process of autophagy [35]. Autophagy, a process that can help maintain cell homeostasis, is an important adaptation involved in tumorigenesis. One study indicated that the MAPK signaling pathway is related to the anti-migration effect of tumors via the inhibition of MMP2/-9 activity [36]. The MAPK signaling pathway was activated by OPN in our study, which showed that OPN might act as an important factor in regulating cell autophagy, as well as 


\section{Cellular Physiology Cell Physiol Biochem 2017;41:1851-1864 and Biochemistry Publisned online: April U3, $2017 \quad \begin{aligned} & \text { D 2017 The Authors. } \\ & \text { www.karger.com/cpb }\end{aligned}$ \\ Huang et al.: Osteopontin Inhibits Apoptosis and Autophagy in Colorectal Cancer}

cell migration and invasion. OPN might regulate cell autophagy through different pathways. Zhang et al. [9] demonstrated that OPN knockdown inhibits $\alpha v \beta 3$-induced cell metastasis and activates the PI3K/Akt/mTOR pathway. In addition, OPN can promote cell migration and invasion and inhibit autophagy by binding integrin $\alpha v \beta 3$, and this further supports the notion that OPN can inhibit cell autophagy. Chang et al. [37] demonstrated that suppressing OPN can promoteBeclin1-induced autophagy in lung cancer cells. However, OPN might also act on different pathways and on different cells. For example, one study showed that OPN can stimulate autophagy in vascular smooth muscle cells via the integrin/CD44 and p38 MAPK pathways, and this result appears to contradict our data [28]. We suppose that OPN may regulate cell autophagy differently in different cells: OPN could inhibit cell autophagy in tumor cells, while promoting autophagy in nontumor cells.

Interestingly, in a recent study, Liu et al. [38] found that OPN was capable of binding its receptor $\alpha v \beta 3$ and sustain FoxO3a stability, thus promoting chemoresistance in hepatocellular carcinoma by inducing cell autophagy. However, Chang et al. indicated that knockdown of OPN could induce autophagy in lung cancer cells, thus negating radioresistance in cancer cells. Autophagy is a complex process, which plays a dual role in regulating tumor carcinogenesis. We hypothesized that OPN may also have a dual regulatory function in tumor cell autophagy.

The Mitogen-Activated Protein Kinase (MAPK) signaling pathway is involved in multiple physiological and pathological processes, such as cell growth, cell differentiation, inflammatory responses, and reaction to stress $[39,40]$. Many stimulators such as growth factors, cytokines, radiation, as well as OPN, can inactivate the MAPK pathway, resulting in various biological effects [41]. P38 MAPK, one of the subgroups of MAPK, is associated with the biological processes of CRC cells. Grossi et al. [42] reported that the p38 $\alpha$ MAPK pathway might act as an oncogenic pathway that could regulate cell invasion and angiogenesis in CRC. In our study, the expression of autophagy-related genes and the LC3-II/LC3-I protein ratio in the anti-MAPK group were higher than in the anti-MAPK+OPN group, which indicates that OPN might regulate cell autophagy not only in the MAPKs pathway. The PI3K/Akt/mTOR pathway is an important pathway that can regulate autophagy in tumor cells, but further studies are needed to determine whether OPN might regulate cell autophagy via the PI3K/ Akt/mTOR pathway.

Our study had some deficiencies. It is known that OPN can regulate cell autophagy via multiple signaling pathways, and more potential pathways, such as the PI3K/Akt pathway, should be analyzed. Integrin has many receptors, but we only performed Western blot analysis on the $\alpha v \beta 3$ receptor, and we did not analyze systematically whether OPN might regulate cell autophagy by the integrin pathway. Further studies should be done to clarify how OPN regulates CRC cell autophagy.

In summary, we reveled that OPN can promote CRC cell proliferation, migration, and invasion, as well as inhibit cell apoptosis and autophagy in vitro. We hypothesize that OPN might inhibit CRC cell autophagy through the p38-MAPK signaling pathway. Identifying the molecular mechanism of OPN's effect on autophagy in CRC will shed light on the mechanisms involved in CRC cell progression and provide us with a new therapeutic target for the treatment of patients with CRC.

\section{Acknowledgements}

This work were supported by Shanghai Municipal Bureau of Health Fund (No.20134242), Shanghai Committee of Science and Technology Fund (No.15ZR1437500).

\section{Disclosure Statement}

All the authors declare no conflict of interest. 


\section{Cellular Physiology Cell Physiol Biochem 2017;41:1851-1864 \begin{tabular}{l|l|l}
\hline DOI: 10.1159/000471933 & () 2017 The Author(s). Published by S. Karger AG, Basel
\end{tabular}

Huang et al.: Osteopontin Inhibits Apoptosis and Autophagy in Colorectal Cancer

\section{References}

1 McNair AG, Whistance RN, Forsythe RO, Macefield R, Rees J, Pullyblank AM, Avery KN, Brookes ST, Thomas MG, Sylvester PA, Russell A, Oliver A, Morton D, Kennedy R, Jayne DG, Huxtable R, Hackett R, Dutton SJ, Coleman MG, Card M, Brown J, Blazeby JM: Core Outcomes for Colorectal Cancer Surgery: A Consensus Study. PLoS Med 2016;13:e1002071.

2 Yatsuoka T, Nishimura Y, Sakamoto H, Tanaka Y, Kurozumi M: [Lymph node metastasis of colorectal cancer with submucosal invasion]. Gan To Kagaku Ryoho 2013;40:2041-2043.

-3 Shi Y, Huang XX, Chen GB, Wang Y, Zhi Q, Liu YS, Wu XL, Wang LF, Yang B, Xiao CX, Xing HQ Ren JL, Xia Y, Guleng B: Dragon (RGMb) induces oxaliplatin resistance in colon cancer cells. Oncotarget 2016;7:4802748037.

-4 Tsuprykov O, Chaykovska L, Kretschmer A, Stasch JP, Pfab T, Krause-Relle K, Reichetzeder C, Kalk P, Adamski J, Hocher B: Endothelin-1 Overexpression Improves Renal Function in eNOS Knockout Mice. Cell Physiol Biochem 2015;37:1474-1490.

-5 Zhu Y, Jia H, Chen J, Cui G, Gao H, Wei Y, Lu C, Wang L, Uede T, Diao H: Decreased Osteopontin Expression as a Reliable Prognostic Indicator of Improvement in Pulmonary Tuberculosis: Impact of the Level of Interferon-gamma-Inducible Protein 10. Cell Physiol Biochem 2015;37:1983-1996.

-6 Zhang H, Li L, Dong Q, Wang Y, Feng Q, Ou X, Zhou P, He T, Luo J: Activation of PKA/CREB Signaling is Involved in BMP9-Induced Osteogenic Differentiation of Mesenchymal Stem Cells. Cell Physiol Biochem 2015;37:548-562.

-7 Wild N, Andres H, Rollinger W, Krause F, Dilba P, Tacke M, Karl J: A combination of serum markers for the early detection of colorectal cancer. Clin Cancer Res 2010;16:6111-6121.

> Ng L, Wan TM, Lam CS, Chow AK, Wong SK, Man JH, Li HS, Cheng NS, Pak RC, Cheung AH, Yau TC, Lo OS, Foo DC, Poon JT, Poon RT, Pang RW, Law WL: Post-operative plasma osteopontin predicts distant metastasis in human colorectal cancer. PLoS One 2015;10:e0126219.

-9 Zhang H, Guo M, Chen JH, Wang Z, Du XF, Liu PX, Li WH: Osteopontin knockdown inhibits alphav,beta3 integrin-induced cell migration and invasion and promotes apoptosis of breast cancer cells by inducing autophagy and inactivating the PI3K/Akt/mTOR pathway. Cell Physiol Biochem 2014;33:991-1002.

$\checkmark 10$ Sun CC, Qu XJ, Gao ZH: Arginine-Glycine-Aspartate-Binding Integrins as Therapeutic and Diagnostic Targets. Am J Ther 2016;23:e198-207.

11 Sun SJ, Wu CC, Sheu GT, Chang HY, Chen MY, Lin YY, Chuang CY, Hsu SL, Chang JT: Integrin beta3 and CD44 levels determine the effects of the OPN-a splicing variant on lung cancer cell growth. Oncotarget 2016;7:55572-55584.

12 Rodrigues LR, Teixeira JA, Schmitt FL, Paulsson M, Lindmark-Mansson H: The role of osteopontin in tumor progression and metastasis in breast cancer. Cancer Epidemiol Biomarkers Prev 2007;16:1087-1097.

- 13 Kurisetty VV, Johnston PG, Johnston N, Erwin P, Crowe P, Fernig DG, Campbell FC, Anderson IP, Rudland PS, El-Tanani MK: RAN GTPase is an effector of the invasive/metastatic phenotype induced by osteopontin. Oncogene 2008;27:7139-7149.

14 Mi Z, Guo H, Russell MB, Liu Y, Sullenger BA, Kuo PC: RNA aptamer blockade of osteopontin inhibits growth and metastasis of MDA-MB231 breast cancer cells. Mol Ther 2009;17:153-161.

15 Mony VK, Benjamin S, O'Rourke EJ: A lysosome-centered view of nutrient homeostasis. Autophagy 2016;12:619-631.

16 de Andrade Ramos BR, Witkin SS: The influence of oxidative stress and autophagy cross regulation on pregnancy outcome. Cell Stress Chaperones 2016;21:755-762.

17 Siracusano G, Venuti A, Lombardo D, Mastino A, Esclatine A, Sciortino MT: Early activation of MyD88mediated autophagy sustains HSV-1 replication in human monocytic THP-1 cells. Sci Rep 2016;6:31302.

18 Ryter SW, Nakahira K, Haspel JA, Choi AM: Autophagy in pulmonary diseases. Annu Rev Physiol 2012;74:377-401.

19 Ntsapi C, Loos B: Caloric restriction and the precision-control of autophagy: A strategy for delaying neurodegenerative disease progression. Exp Gerontol 2016;83:97-111.

20 Burada F, Nicoli ER, Ciurea ME, Uscatu DC, Ioana M, Gheonea DI: Autophagy in colorectal cancer: An important switch from physiology to pathology. World J Gastrointest Oncol 2015;7:271-284.

-21 vom Dahl S, Schliess F, Reissmann R, Gorg B, Weiergraber O, Kocalkova M, Dombrowski F, Haussinger D: Involvement of integrins in osmosensing and signaling toward autophagic proteolysis in rat liver. J Biol Chem 2003;278:27088-27095.

22 Ma Y, Li M, Si J, Xiong Y, Lu F, Zhang J, Zhang L, Zhang P, Yang Y: Blockade of Notch3 inhibits the stem-like property and is associated with ALDH1A1 and CD44 via autophagy in non-small lung cancer. Int J Oncol 


\section{Cellular Physiology Cell Physiol Biochem 2017;41:1851-1864 \begin{tabular}{l|l} 
and Biochemistry Publisned onlIne: AprIIU3, 2017 & $\begin{array}{l}\text { () 2017 The Author(s). Published by S. Karger AG, Basel } \\
\text { www.karger.com/cpb }\end{array}$
\end{tabular}}

Huang et al.: Osteopontin Inhibits Apoptosis and Autophagy in Colorectal Cancer

2016;48:2349-2358.

23 Luo DH, Chen QY, Liu H, Xu LH, Zhang HZ, Zhang L, Tang LQ, Mo HY, Huang PY, Guo X, Mai HQ: The independent, unfavorable prognostic factors endothelin A receptor and chemokine receptor 4 have a close relationship in promoting the motility of nasopharyngeal carcinoma cells via the activation of AKT and MAPK pathways. J Transl Med 2013;11:203.

-24 Huang C, Shen S, Ma Q, Chen J, Gill A, Pollock CA, Chen XM: Blockade of KCa3.1 ameliorates renal fibrosis through the TGF-beta1/Smad pathway in diabetic mice. Diabetes 2013;62:2923-2934.

25 Thorsen SB, Lundberg M, Villablanca A, Christensen SL, Belling KC, Nielsen BS, Knowles M, Gee N, Nielsen HJ, Brunner N, Christensen IJ, Fredriksson S, Stenvang J, Assarsson E: Detection of serological biomarkers by proximity extension assay for detection of colorectal neoplasias in symptomatic individuals. J Transl Med 2013;11:253.

-26 Likui W, Hong W, Shuwen Z: Clinical significance of the upregulated osteopontin mRNA expression in human colorectal cancer. J Gastrointest Surg 2010;14:74-81.

27 Li Y, Xie Y, Cui D, Ma Y, Sui L, Zhu C, Kong H, Kong Y: Osteopontin Promotes Invasion, Migration and Epithelial-Mesenchymal Transition of Human Endometrial Carcinoma Cell HEC-1A Through AKT and ERK1/2 Signaling. Cell Physiol Biochem 2015;37:1503-1512.

28 Zheng YH, Tian C, Meng Y, Qin YW, Du YH, Du J, Li HH: Osteopontin stimulates autophagy via integrin/CD44 and p38 MAPK signaling pathways in vascular smooth muscle cells. J Cell Physiol 2012;227:127-135.

29 Zhang R, Yang W, Li YC, Zhang GJ, Yao K, Hu R, Wu B: The OPN gene polymorphism confers the susceptibility and response to Ara-C based chemotherapy in Chinese AML patients. Cell Physiol Biochem 2015;35:175-183.

-30 Schurpf T, Chen Q Liu JH, Wang R, Springer TA, Wang JH: The RGD finger of Del-1 is a unique structural feature critical for integrin binding. Faseb j 2012;26:3412-3420.

- 31 Chen YJ, Wei YY, Chen HT, Fong YC, Hsu CJ, Tsai CH, Hsu HC, Liu SH, Tang CH: Osteopontin increases migration and MMP-9 up-regulation via alphavbeta3 integrin, FAK, ERK, and NF-kappaB-dependent pathway in human chondrosarcoma cells. J Cell Physiol 2009;221:98-108.

- 32 Anborgh PH, Mutrie JC, Tuck AB, Chambers AF: Role of the metastasis-promoting protein osteopontin in the tumour microenvironment. J Cell Mol Med 2010;14:2037-2044.

33 Sharon Y, Raz Y, Cohen N, Ben-Shmuel A, Schwartz H, Geiger T, Erez N: Tumor-derived osteopontin reprograms normal mammary fibroblasts to promote inflammation and tumor growth in breast cancer. Cancer Res 2015;75:963-973.

-34 Fok TC, Lapointe H, Tuck AB, Chambers AF, Jackson-Boeters L, Daley TD, Darling MR: Expression and localization of osteopontin, homing cell adhesion molecule/CD44, and integrin alphavbeta3 in mucoepidermoid carcinoma and acinic cell adenocarcinoma of salivary gland origin. Oral Surg Oral Med Oral Pathol Oral Radiol 2014;118:320-329.

-35 Wang Q, Ren J: mTOR-Independent autophagy inducer trehalose rescues against insulin resistance-induced myocardial contractile anomalies: Role of p38 MAPK and Foxo1. Pharmacol Res 2016;111:357-373.

-36 Luo M, Liu Q, He M, Yu Z, Pi R, Li M, Yang X, Wang S, Liu A: Gartanin induces cell cycle arrest and autophagy and suppresses migration involving PI3K/Akt/mTOR and MAPK signalling pathway in human glioma cells. J Cell Mol Med 2017;21:46-57.

- 37 Chang SH, Minai-Tehrani A, Shin JY, Park S, Kim JE, Yu KN, Hong SH, Hong CM, Lee KH, Beck GR, Jr., Cho MH: Beclin1-induced autophagy abrogates radioresistance of lung cancer cells by suppressing osteopontin. J Radiat Res 2012;53:422-432.

- 38 Liu G, Fan X, Tang M, Chen R, Wang H, Jia R, Zhou X, Jing W, Wang H, Yang Y, Yin F, Wei H, Li B, Zhao J: Osteopontin induces autophagy to promote chemo-resistance in human hepatocellular carcinoma cells. Cancer Lett 2016;383:171-182.

-39 Guo C, Xia Y, Niu P, Jiang L, Duan J, Yu Y, Zhou X, Li Y, Sun Z: Silica nanoparticles induce oxidative stress, inflammation, and endothelial dysfunction in vitro via activation of the MAPK/Nrf2 pathway and nuclear factor-kappaB signaling. Int J Nanomedicine 2015;10:1463-1477.

-40 Pizzute T, Li J, Zhang Y, Davis ME, Pei M: Fibroblast Growth Factor Ligand Dependent Proliferation and Chondrogenic Differentiation of Synovium-Derived Stem Cells and Concomitant Adaptation of Wnt/ Mitogen-Activated Protein Kinase Signals. Tissue Eng Part A 2016;22:1036-1046.

-41 Di Girolamo N, Wakefield D, Coroneo MT: UVB-mediated induction of cytokines and growth factors in pterygium epithelial cells involves cell surface receptors and intracellular signaling. Invest Ophthalmol Vis Sci 2006; 47:2430-2437.

42 Grossi V, Peserico A, Tezil T, Simone C: p38alpha MAPK pathway: a key factor in colorectal cancer therapy and chemoresistance. World J Gastroenterol 2014;20:9744-9758. 